\title{
Attitudes of Klinefelter men and their relatives towards TESE-ICSI
}

\author{
Merel C. Maiburg • Alissia C. Hoppenbrouwers • \\ Henk F. van Stel • Jacques C. Giltay
}

Received: 30 April 2011 / Accepted: 14 June 2011 / Published online: 30 June 2011

(C) The Author(s) 2011. This article is published with open access at Springerlink.com

\begin{abstract}
Purpose At the start of the implementation of TESE-ICSI for Klinefelter men in the Netherlands, we aimed to evaluate their wish to father children and their attitudes towards this artificial reproduction technique.

Methods Questionnaires were distributed to members of the Dutch Klinefelter Association $(n=365)$ and to Klinefelter cases known at our Department $(n=58)$. Questions addressed several aspects: socio-demographic characteristics, ascertainment of diagnosis, children and child wish, and TESE-ICSI. Data were characterized using descriptive statistics.

Results A total of 260 questionnaires (corresponding to 194 cases, 46\%) were returned. A possible wish to father children was reported by $90 \%$ of Klinefelter men. $70 \%$ of Klinefelter men and $74 \%$ of their partners would (probably) opt for TESE-ICSI.

Conclusion The majority of Dutch Klinefelter men and their partners desire to have children and have a positive attitude towards TESE-ICSI. Concerns include the risk of
\end{abstract}

Capsule The majority of Dutch Klinefelter men and their partners desire to have children and have a positive attitude towards TESE-ICSI.

Electronic supplementary material The online version of this article (doi:10.1007/s10815-011-9603-z) contains supplementary material, which is available to authorized users.

M. C. Maiburg $(\bowtie) \cdot$ A. C. Hoppenbrouwers $\cdot$ J. C. Giltay

Department of Medical Genetics,

University Medical Center Utrecht,

Utrecht, The Netherlands

e-mail: m.maiburg@umcutrecht.nl

H. F. van Stel

Julius Center for Health Sciences and Primary Care,

University Medical Center Utrecht,

Utrecht, The Netherlands congenital malformations/developmental delay of the child and the limited success rate of TESE-ICSI.

Keywords Klinefelter syndrome · Testicular sperm extraction · Intracytoplasmic sperm injection · Child wish . Questionnaire

\section{Introduction}

Klinefelter syndrome [1] is the most common chromosomal abnormality found in humans (one in 500-1,000 males) [2], and the most frequent genetic cause of azoospermia [3]. In $80-90 \%$ of all cases a $47, \mathrm{XXY}$ karyotype is found, the remaining cases showing a mosaic karyotype (46,XY/47, $\mathrm{XXY}$ ) or additional X-chromosomes (e.g. 48,XXXY or 48, $\mathrm{XXYY})[2,4,5]$. If the diagnosis is made $(75 \%$ of the expected number of Klinefelter men are undiagnosed), this is most often at adult age if karyotyping is performed because of hypogonadism/infertility [6]. In the vast majority of cases, Klinefelter men are azoospermic.

Several reports have been published on successful fertility treatment of men with Klinefelter syndrome using Testicular Sperm Extraction (TESE) combined with Intracytoplasmic Sperm Injection (ICSI), as recently reviewed by Fullerton et al. [7]. In about half (44-55\%) of the Klinefelter men sperm can be recovered from the testes [7], with an average pregnancy rate after ICSI of $20-25 \%$ per treatment cycle $[8,9]$. These success rates are similar to those of TESE in azoospermic men with other or unknown etiology [7]. This treatment offers Klinefelter men the opportunity to father their own genetic child.

In the Netherlands, TESE-ICSI has been permitted on a limited scale and restricted to infertile men with a normal (46,XY) karyotype since June 2007. Klinefelter men had 
been excluded from TESE-ICSI treatment, due to the fear of a possible increased risk of chromosomal abnormalities in their offspring. However, only one XXY pregnancy in over a hundred children born after TESE-ICSI in males with nonmosaic Klinefelter syndrome has been reported in the literature [5]. Now that the risk seems to be similar to that after TESEICSI in karyotypically normal males [10, 11], albeit higher compared to children born after natural conception (in whom an incidence of (unbalanced) chromosomal aberrations of $0.4 \%$ has been reported [12]), recently a protocol for applying TESE-ICSI treatment for Klinefelter men in the Netherlands was approved by the Central Committee on Research involving Human Subjects ('CCMO').

Prior to the implementation of TESE-ICSI for Klinefelter men in the Netherlands, we were interested to learn more about the views on TESE-ICSI of Dutch Klinefelter men and their partners. In addition we aimed to get an impression of the wish to father children in a cohort of Klinefelter men diagnosed for reasons other than infertility.

\section{Methods}

\section{Questionnaire design}

A study-specific questionnaire was designed to investigate 1) child wish/the need for TESE-ICSI in Klinefelter syndrome, 2) perceptions of the risks, success rate and other factors influencing the decision (not) to opt for TESEICSI and 3) in the case of Klinefelter boys, whether their parents think this technique would be a valuable option for future fertility treatment of their sons. Items were generated based on expert opinions and research literature. The questionnaire was designed in a way that both Klinefelter men, their partners or parents of Klinefelter boys could complete the same version of the questionnaire.

Respondents were asked to document whether they had Klinefelter syndrome themselves, were a partner of a Klinefelter man or parent of a son $(<18$ years $)$ with Klinefelter syndrome. Questions were organized in four categories (supplementary data 1): A) socio-demographic characteristics, B) ascertainment of diagnosis, C) related to children and child wish, D) the respondents views on different aspects of TESE-ICSI treatment (as defined in Table 2). Finally, respondents had the possibility to describe in their own words their views on TESE-ICSI as a treatment option for Klinefelter men in the Netherlands. Informative parts of these answers were included in the results.

For questions in category D, a five-point answer scale was used (ranging from not important at all to very important) and the mean score for the different questions was determined, defining the individual's general risk perception (supplementary data 1). For some questions that seemed not applicable for parents (e.g. questions about considerations (not) to opt for TESE-ICSI), they were asked to answer these questions as if they were in their son's situation (i.e. TESE-ICSI as the only option to conceive their own genetic child).

Content validity of this self-developed questionnaire was checked by a multidisciplinary team consisting of clinical geneticists, a pediatrician and an epidemiologist. Furthermore, the questionnaire was tested for comprehensiveness and comprehensibility by the board of the Dutch Klinefelter Association.

\section{Questionnaire distribution}

Questionnaires were distributed to all known cases of Klinefelter syndrome at our Medical Genetics Department $(n=58)$ and through the Dutch Klinefelter Association to all of their members ( $n=365$, anonymously for the authors), see flowchart (Fig. 1). Members of the Dutch Klinefelter Association include men with Klinefelter syndrome, partners of Klinefelter men, parents of Klinefelter boys and clinicians or individuals otherwise involved. Addressees belonging to one of the latter two categories were asked to indicate this and were excluded from the study. All addressees received two identical questionnaires to allow both the Klinefelter man and his partner or both parents of Klinefelter boys $(<18$ years of age) to complete separate questionnaires independently. An appendix, providing information about the TESE-ICSI procedure, the success rate and possible risks involved, was attached to the questionnaire (supplementary data 2). Two months after the original mailing, a reminder letter was sent to all addressees.

\section{Statistical analysis}

Uncompleted questionnaires (i.e. $>50 \%$ missing values) were excluded from further analysis. The remaining questionnaires were characterized using descriptive statistics. Valid percentages are presented; when missing values

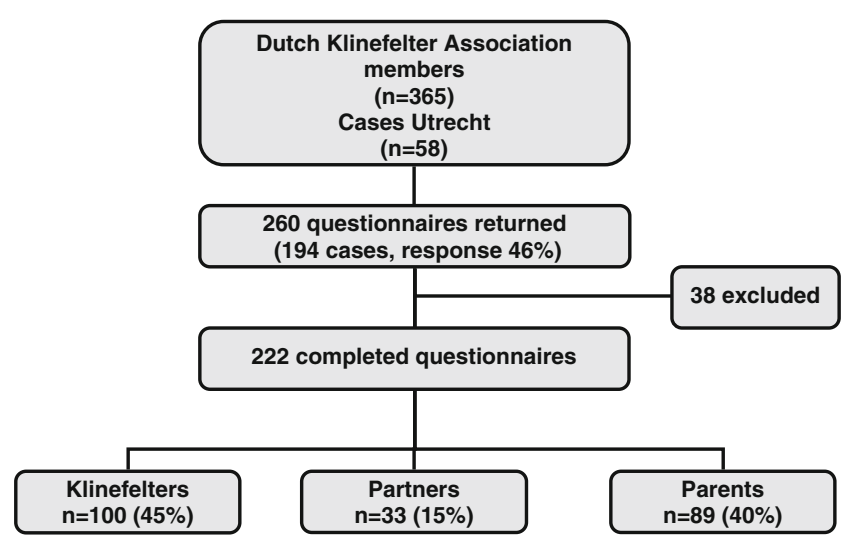

Fig. 1 Flowchart 
were $>10 \%$ this was stated. To determine differences between groups, we used the Mann-Whitney U-test or Independent T-test, depending on the variable [13]. Analysis of all data was performed using SPSS (Statistical Package for the Social Sciences) 15.0.

\section{Results}

A total of 260 questionnaires (corresponding to 194 cases, $46 \%$ ) were returned. Of those, 38 were excluded, because either the respondents did not belong to our target group or the questionnaires were not completed. Of all included questionnaires $(n=222), 100(45 \%)$ were completed by Klinefelter men, $33(15 \%)$ by partners and $89(40 \%)$ by parents of Klinefelter boys (flowchart, Fig. 1).

Sociodemographic characteristics of respondents

Baseline characteristics are shown in Table 1. The mean age of Klinefelter men at the time of completing the questionnaire was 40.6 years (range 18-66 years). Their partners mean age was 40.0 years (range 17-62 years). More than half (52\%) of the Klinefelter men had a partner.

Ascertainment of diagnosis

In $34 \%$ of all adult cases, infertility was the primary reason to perform karyotyping. About half $(53 \%)$ of the boys with Klinefelter syndrome were diagnosed prenatally. Other reasons leading to the diagnosis are shown in Table 1. The mean age at diagnosis (of the postnatally diagnosed cases) was 25 years (range 1 to 62 years) for the adult group and 7 years (range 0 to 15 years) for the Klinefelter boys. Seventy-nine percent of all adult cases and $80 \%$ of the Klinefelter boys showed a $47, \mathrm{XXY}$ karyotype.

Children/the wish to have children

Of all Klinefelter men that responded to this question ( $n=$ 93), two mosaic $\mathrm{XXY} / \mathrm{XY}$ men reported to have their own

Table 1 Baseline characteristics of respondents $(n=222)$

\begin{tabular}{|c|c|c|c|}
\hline & Klinefelters & Partners & Parents (/KS boys) \\
\hline$n$ & $100(45 \%)$ & $33(15 \%)$ & 89 (40\%) (57 KS boys) \\
\hline Mean age (range) & $40(18-66)$ & $40(17-62)$ & $47(32-60)$ \\
\hline Mean age of diagnosis in years (range) of postnatal cases & $25(1-62)$ & $\mathrm{na}^{\mathrm{a}}$ & $7(0-15)$ \\
\hline Education & $(n=98)$ & $(n=32)$ & $(n=88)$ \\
\hline Lower & $27(28 \%)$ & $8(25 \%)$ & $12(14 \%)$ \\
\hline Middle & $53(54 \%)$ & $17(53 \%)$ & $41(47 \%)$ \\
\hline Higher & $18(18 \%)$ & $7(22 \%)$ & $35(40 \%)$ \\
\hline Religion & $(n=98)$ & $(n=33)$ & $(n=89)$ \\
\hline None & $39(40 \%)$ & $15(46 \%)$ & $38(43 \%)$ \\
\hline Roman catholic & $30(31 \%)$ & $6(18 \%)$ & $35(39 \%)$ \\
\hline Protestant & $13(13 \%)$ & $9(27 \%)$ & $11(12 \%)$ \\
\hline Other & $16(16 \%)$ & $3(9 \%)$ & $5(6 \%)$ \\
\hline Karyotype & $(n=98)$ & $\mathrm{na}^{\mathrm{a}}$ & $(n=56)$ \\
\hline $47, \mathrm{XXY}$ & $77(79 \%)$ & & $45(80 \%)$ \\
\hline $46, \mathrm{XY} / 47, \mathrm{XXY}$ & $6(6 \%)$ & & $4(7 \%)$ \\
\hline Other/unknown & $15(15 \%)$ & & $7(13 \%)$ \\
\hline Ascertainment of diagnosis ${ }^{\mathrm{b}}$ & $(n=94)$ & $\mathrm{na}^{\mathrm{a}}$ & $(n=57)$ \\
\hline Prenatal cases & $1(1 \%)$ & & $30(53 \%)$ \\
\hline Postnatal cases & $93(99 \%)$ & & $27(47 \%)$ \\
\hline - Congenital malformations/dysmorphism & $-37(39 \%)$ & & $-14(52 \%)$ \\
\hline - Learning problems/MR/behaviour & $-16(17 \%)$ & & $-19(70 \%)$ \\
\hline - Infertility & $-32(34 \%)$ & & $-0(0 \%)$ \\
\hline - Other ${ }^{\mathrm{c}}$ & $-22(23 \%)$ & & $-5(19 \%)$ \\
\hline
\end{tabular}

${ }^{\mathrm{a}}$ Not applicable

${ }^{b}$ Total $>100 \%$ because of overlap between subgroups (eg. congenital malformations/dysmorphisms and learning problems/MR)

${ }^{\mathrm{c}}$ Including osteoporosis, leg ulcers and excessive growth velocity (adults) and abnormal growth pattern and epilepsy (boys) 
genetic children, one conceived after a spontaneous pregnancy and one following IVF-ICSI treatment. Another nine Klinefelter men had one or more children conceived after sperm donation, three following IVF-ICSI with donor sperm, four Klinefelter men had (an) adopted or foster child (ren) and seven had one or more children from a previous relationship of their partner. In total 25 (27\%) Klinefelter men had one or more children. Of those Klinefelter men diagnosed because of other reasons than infertility $(n=62), 9(15 \%)$ had at least one child.

Possible child wish (either in the past, present, or future) was reported by $90 \%$ of Klinefelter men; $61 \%$ of all Klinefelter men have (had) a strong child wish. Klinefelter men diagnosed because of other reasons than infertility reported a (possible) child wish in $84 \%$ of cases $(n=52)$, with almost half $(48 \%)$ of the cohort reporting a strong child wish. Of all partners, 94\% reported a (possible) child wish, while $79 \%$ had (had) a strong child wish.

Of all Klinefelter men, $44 \%$ reported that a life without children would be (much) less valuable compared to a life with children. For partners and parents these numbers were $71 \%$ and $87 \%$ respectively.

"I have always had a strong desire to have my own children. I cannot accept the fact that this is not possible for me. I feel inferior and left behind compared to people that can have their own children." (Klinefelter man, 48 years)

\section{Respondents views on TESE-ICSI}

\section{Considerations in their choice for TESE-ICSI}

In general, the risk of congenital malformations and/or developmental delay in the offspring was the most important aspect in considering TESE-ICSI ('important' or 'very important' according to $70 \%$ of Klinefelter men ( $11 \%$ missing values), $58 \%$ of partners and $58 \%$ of parents), followed by the success rate of TESE-ICSI treatment ( $46 \%$, $59 \%$ and $42 \%$ respectively) (Table 2 ).

Despite the majority of respondents being religious, in only $3 \%$ of Klinefelter men, $6 \%$ of their partners and $1 \%$ of parents, religion played an important role, similar to the judgement 'you should not intervene with nature', which was 'important' or 'very important' for only $1 \%, 3 \%$ and $4 \%$ respectively.

\section{Success rate of TESE-ICSI}

The success rate of TESE-ICSI in Klinefelter men (a maximum of $25 \%$ a priori chance of pregnancy) is judged as 'good' or 'very good' by $45 \%$ of all respondents $(41 \%$ of Klinefelter men, $34 \%$ of partners and $54 \%$ of parents).
"Whether you have to tell your son that he is infertile, or that there might be a chance to father his own children, is quite a difference" (mother of Klinefelter boy)

"More important than the actual success rate is the fact that there is a chance at all." (father of Klinefelter boy)

In contrast, the success rate is judged as 'moderate' or 'bad' by $31 \%$ (Klinefelter men $33 \%$, partners $47 \%$ and parents $24 \%$ ).

"The success rate is too low compared to the hope that's given." (Klinefelter man, 32 years)

"I think it would be hard to deal with the disappointment when there is no success, and that chances are $75 \%$." (mother of Klinefelter boy)

\section{Would Klinefelter men and their partners choose TESE-ICSI?}

Seventy percent of the Klinefelter men $(75 \%$ of those diagnosed because of infertility and $66 \%$ of those diagnosed for other reasons) would (probably) opt for TESEICSI, compared to $74 \%$ of their partners. Ninety-five percent of the parents estimated this treatment a valuable option for their sons (Fig. 2).

"I think this is very important for the self-confidence of the Klinefelter man." (partner of Klinefelter man)

Only a few respondents are more cautious or express their feelings against TESE-ICSI:

"This possibility brings hope and gives a chance of parenthood, but also creates confusion, uncertainty and false hope." (mother of Klinefelter boy)

"Accept that men with Klinefelter syndrome can't have children... there are too many children in the world without parents, so adopt them" (Klinefelter man, 56 years)

Those respondents that would (probably) not choose to have TESE-ICSI express less desire to have children $(p=<0.001)$, score significantly higher on 'general risk perception' (mean risk score 3.6 vs $2.9 ; p=<0.001$ ), and have a more pessimistic view of the success rate $(p=0.001)$ compared to those that would (probably) opt for TESE-ICSI.

For Klinefelter men, the mean age of those that would (probably) opt for TESE-ICSI was significantly lower than the age of those who would (probably) not (39.0 years vs 45.3 years, $p=0.020$ ). A similar difference was found for partners of Klinefelter men, although not significant (mean age 37.7 age vs. 44.8 years, $p=0.121$ ). 
Table 2 Considerations on TESE-ICSI treatment

\begin{tabular}{|c|c|c|c|c|c|c|c|c|c|}
\hline & \multicolumn{3}{|c|}{ (Very) important (\%) } & \multicolumn{3}{|l|}{ Neutral (\%) } & \multicolumn{3}{|c|}{ Not important (at all) (\%) } \\
\hline & Klinefelters & Partners & Parents & Klinefelters & Partners & Parents & Klinefelters & Partners & Parents \\
\hline Male burden ${ }^{\mathrm{a}}$ & 31 & 39 & 19 & 30 & 38 & 19 & 39 & 23 & 62 \\
\hline (Transient) $\downarrow$ of testosterone & 30 & 19 & 13 & 29 & 47 & 21 & 41 & 34 & 66 \\
\hline Female burden ${ }^{\mathrm{b}}$ & 43 & 38 & 31 & 34 & 31 & 30 & 23 & 31 & 39 \\
\hline Risk of MCA/MR ${ }^{c}$ & 70 & 58 & 58 & 20 & 26 & 30 & 10 & 16 & 12 \\
\hline Role of religion ${ }^{\mathrm{d}}$ & 3 & 6 & 1 & 8 & 16 & 5 & 66 & 38 & 75 \\
\hline Interfering with nature ${ }^{\mathrm{d}}$ & 1 & 3 & 4 & 9 & 19 & 12 & 82 & 61 & 78 \\
\hline $\begin{array}{l}\text { Limited experience in the } \\
\text { Netherlands }{ }^{\mathrm{d}}\end{array}$ & 22 & 31 & 20 & 39 & 50 & 31 & 33 & 16 & 47 \\
\hline Success rate ${ }^{\mathrm{d}}$ & 46 & 59 & 42 & 27 & 13 & 28 & 26 & 28 & 29 \\
\hline
\end{tabular}

${ }^{\text {a }}$ TESE procedure (possible bleeding, infection or pain)

${ }^{\mathrm{b}}$ IVF procedure (possible bleeding, infection or pain; risk of ovarian overstimulation)

${ }^{\mathrm{c}}$ Multiple congenital anomalies/mental retardation

${ }^{\mathrm{d}}$ Some respondents did not answer this question or indicated that the item was not applicable for them, therefore the total of the indicated percentages does not reach $100 \%$

\section{Discussion}

Our study shows that the majority of Dutch Klinefelter men and their partners desire to have children and have a positive attitude towards TESE-ICSI treatment. Even those who would (probably) refrain from treatment, think TESE-ICSI can be a valuable option for others. Their arguments in favour of TESE-ICSI are the chance to father their own child, the fact that TESE-ICSI is successfully applied abroad and the resulting increase in self-confidence of the Klinefelter man. The arguments against TESE-ICSI are the possible risk of congenital malformations or developmental delay of the child, and the limited success rate of TESE-ICSI.

Our response rate $(46 \%)$ is likely to be underestimated, because cases from the Dutch Klinefelter Association (anonymous to the authors) and cases of our own department probably partially overlapped, so in fact the total number of unique addressees was somewhat smaller. A number of addressees mistakenly thought they were not in our target

Fig. 2 Would you opt for TESE-ICSI?

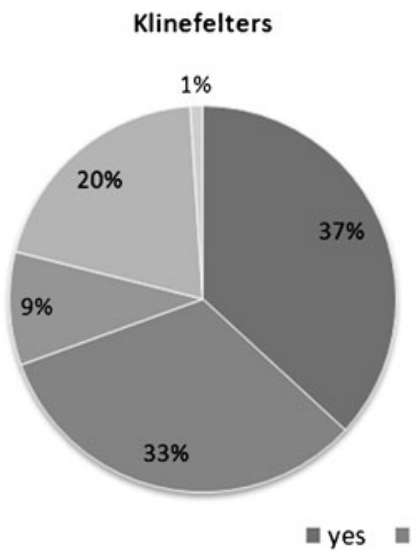

group and returned the questionnaire uncompleted (these were included in the response rate, but later excluded, see flowchart). In addition, several respondents stated that they returned only one of the two questionnaires, and answered the questions also on behalf of their partner.

Our cohort was similar to other published Klinefelter cohorts with regard to the distribution of the karyotypes ( $80 \%$ non-mosaic XXY karyotypes, compared to $80-90 \%$ reported in the literature $[2,4,5])$ and distribution of indications for karyotyping [6]. The proportion of (adult) males karyotyped because of infertility/hypogonadism was lower in our study compared to that of Abramsky et al. [6] ( $34 \%$ vs. $54 \%$ ), probably because we did not include cases with gynecomastia in this subgroup.

Since the average age of the Klinefelter men in our study was 40 years, for a substantial number of them, questions about child wish and reproductive options are not a current issue (anymore). Consequently they will have answered these questions 'retrospectively', which might not entirely represent choices they would have made when they were

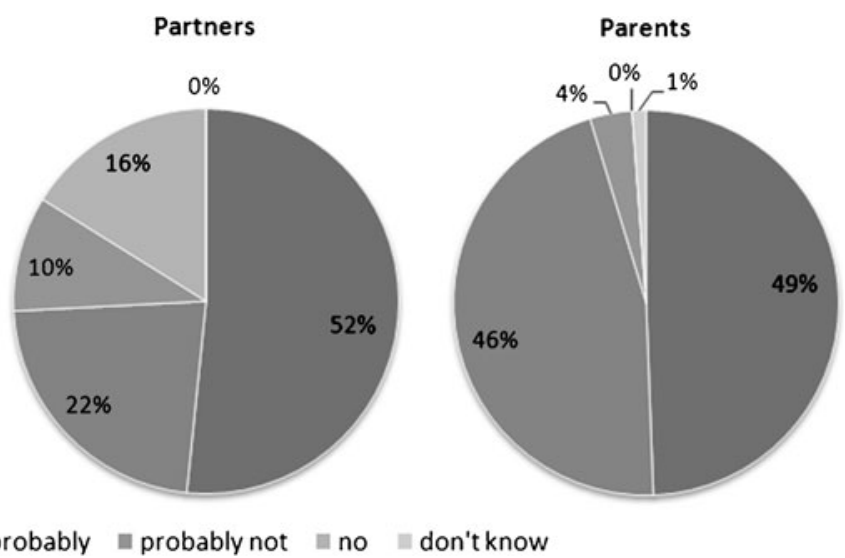


younger. Indeed, our data showed that those Klinefelter men who would (probably) opt for TESE-ICSI were significantly younger than those who would (probably) not.

To the best of our knowledge, no data are available concerning the desire of parenthood in the general (Dutch) population. "Statistics Netherlands" (CBS) does report "the number of (expected to be) childless women" (born between 1960 and 1964) to be $20 \%$ [14]. The percentage of Klinefelter men that desire parenthood in this study $(90 \%)$ is probably overestimated since we are not informed about the desire to father children in the (expected) $75 \%$ undiagnosed Klinefelter men and in non-responders. However, in a sub cohort of Klinefelter men diagnosed because of reasons other than infertility in our study, the vast majority ( $82 \%)$ does have a (possible) child wish.

Addressees were informed about the TESE-ICSI procedure, success rate and possible risks involved in an information letter attached to the questionnaire (supplementary data 1). The actual reading and level of comprehension of this information was not evaluated. However, respondents had the opportunity to contact us using a telephone number provided in the introductory letter. Only a few respondents made use of this, their questions concerning mainly the target group (e.g. 'Am I too old to complete the questionnaire?').

It is possible that their attitudes towards TESE-ICSI might be different following a personal, more profound counselling. However, Vernaeve et al. [15] reported that after a counselling session by a psychologist and gynecologist, the majority $(69 \%)$ of all couples in their study population (357 patients with a severe male factor infertility and 60 with a genetic trait) did want to try new techniques like ICSI, TESE and/or preimplantation genetic diagnosis (PGD), which is similar to the $70 \%$ of Klinefelter men and $74 \%$ of partners opting for TESE-ICSI in our cohort. Also, of 28 men with a Y-deletion described by Nap et al. [16], 79\% chose ICSI (using their own gametes), $7 \%$ opted for donor insemination while $7 \%$ refrained from treatment. Decision making was influenced by the counseling procedure, counselor and available treatment.

We cannot eliminate the possibility that some of the respondents might have felt some tendency to be positive towards TESE-ICSI to promote its availability in the Netherlands. On the other hand, the majority of the items contained in the questionnaire is not related to this potentially political aspect. Moreover, TESE-ICSI is available for Klinefelter men in surrounding countries Belgium and Germany. Indeed, many Dutch Klinefelter men have already gone abroad for TESE-ICSI treatment.

\section{Conclusion}

The majority of Klinefelter men that completed the questionnaire desire to father children. Our study shows that the majority of Dutch Klinefelter men and their partners have a positive attitude towards TESE-ICSI treatment. However, the number of couples ultimately choosing TESE-ICSI is yet to be evaluated.

Open Access This article is distributed under the terms of the Creative Commons Attribution Noncommercial License which permits any noncommercial use, distribution, and reproduction in any medium, provided the original author(s) and source are credited.

\section{References}

1. Klinefelter HF, Reifenstein EC, Albright F. Syndrome characterised by gynecomastia, aspermatogenesis without a-leydigism, and increased excretion of follicle-stimulating hormone. J Clin Endocrinol. 1942;2:615-27.

2. Bojesen A, Juul S, Gravholt CH. Prenatal and postnatal prevalence of Klinefelter syndrome: a national registry study. J Clin Endocrinol Metab. 2003;88:622-6.

3. Tuttelmann F, Gromoll J. Novel genetic aspects of Klinefelter's syndrome. Mol Hum Reprod. 2010;16:386-95.

4. Lanfranco F, Kamischke A, Zitzmann M, Nieschlag E. Klinefelter's syndrome. Lancet. 2004;364:273-83.

5. Giltay JC, Maiburg MC. Klinefelter syndrome: clinical and molecular aspects. Expert Rev Mol Diagn. 2010;10:765-76.

6. Abramsky L, Chapple J. 47, XXY (Klinefelter syndrome) and 47, XYY: estimated rates of and indication for postnatal diagnosis with implications for prenatal counselling. Prenat Diagn. 1997;17:363-8.

7. Fullerton G, Hamilton M, Maheshwari A. Should non-mosaic Klinefelter syndrome men be labelled as infertile in 2009? Hum Reprod. 2010;25:588-97.

8. Devroey P, Van Steirteghem A. A review of ten years experience of ICSI. Hum Reprod Update. 2004;10:19-28.

9. Andersen AN, Goossens V, Ferraretti AP, Bhattacharya S, Felberbaum R, de Mouzon J, et al. Assisted reproductive technology in Europe, 2004: results generated from European registers by ESHRE. Hum Reprod. 2008;23:756-71.

10. Levron J, Aviram-Goldring A, Madgar I, Raviv G, Barkai G, Dor J. Sperm chromosome analysis and outcome of IVF in patients with non-mosaic Klinefelter's syndrome. Fertil Steril. 2004;74:925-9.

11. Denschlag D, Tempfer C, Kunze M, Wolff G, Keck C. Assisted reproductive techniques in patients with Klinefelter syndrome: a critical review. Fertil Steril. 2004;82:775-9.

12. Jacobs PA, Browne C, Gregson N, Joyce C, White H. Estimates of the frequency of chromosome abnormalities detectable in unselected newborns using moderate levels of banding. J Med Genet. 1992;29:103-8.

13. Altman DG. Practical statistics for medical research. 1st ed. London: Chapman \& Hall/CRC; 1990.

14. Statistics Netherlands ("Centraal Bureau voor de Statistiek"). Women and (expected) number of children. Available at: http:// statline.cbs.nl. Accessed June 3, 2011.

15. Vernaeve V, Festre V, Baetens P, Devroey P, Van Steirteghem A, Tournaye H. Reproductive decisions by couples undergoing artificial insemination with donor sperm for severe male infertility: implications for medical counselling. Int J Androl. 2005;28:22-6.

16. Nap AW, Van Golde RJ, Tuerlings JH, De Sutter P, Pieters MH, Giltay JC, et al. Reproductive decisions of men with microdeletions of the Y chromosome: the role of genetic counselling. Hum Reprod. 1999;14:2166-9. 